\title{
PLANNING PRINCIPLES FOR ENHANCING THE IMPLEMENTATION OF A MOBILE ROBOT ON THE CONSTRUCTION SITE
}

\author{
Prof. Dr.-Ing. / Univ. Tokio Thomas Bock \\ Dipl.-Ing. Klaus Kreupl, Dipl.-Ing. Jens Herbst \\ Technische Universitaet Muenchen \\ Lehrstuhl fuer Baurealisierung und Bauinformatik \\ Arcisstrasse 21, D-80333 Muenchen, Germany \\ klaus.kreupl@bri.arch.tu-muenchen.de
}

\begin{abstract}
The main difference between industrial robots which are applied to the prefabrication of building components and the construction robots which are mostly used for on-site work, is its mobility based on interaction with the environment through sensors and built-in intelligence, and the need to cope with the specific conditions on the construction site. The technology needed for these purposes already exists, and can be modified for the particular building task. But nevertheless the implementation of such machines has proved to be difficult for different reasons. The problem is not the robot itself but rather an integrated system of a robot-oriented construction and building process which is essential for an economic implementation of this technology.

The economic success of on-site automation is predetermined very early in the whole process. So the main question is: What are the facts / constraints / impacts / conditions which architects and planners have to consider in order to simplify or even to enable automation in later stages of the construction realisation and what kind of tools and aids can be provided?

In this paper planning principles for enhancing the implementation of a mobile robot on the construction site are introduced. Reengineering the whole process these principles produce an optimization of project results in general.
\end{abstract}

Keywords: Planning Principles, On Site-Automation, Integration of Trades, Site Organization, Constant Data-Flow

\section{INTRODUCTION}

A high degree of automation and integration of different production levels has already been achieved in industrial manufacturing by the application of microelectronics and intelligent control systems. In the construction industry, however, this development is limited so far to computer-aided planning (e.g. designing by CAAD, 3D modelling, calculation of costs and quantities, preparation of project specifications for contract award, static calculations, etc.). Industrial automated processes are only implemented in the production of components in stationary prefabrication plants (e.g. masonry and concrete elements) in order to obtain high-quality results [1].

But there is a high demand for such solutions and the Institut fuer Sozialforschung (Institute for Social Research) estimates an additional market in Germany of approx. 1.2 million individuals willing to invest in residential housing if the object costs were reduced from currently 250,000 Euros down to about 150,000 Euros. Of course the enormously high plot prices contribute to this situation, but the pure construction costs still have a share of approx. $50 \%$ of the total costs. Since there are more possibilities for influence here in relation to the plot prices, strategies within this area are to be developed.

A first step is transferring the value adding processes away from the building site into the fabrication plant: The continuing development of modular and prefabricated systems has a strong impact here.

The conventional building construction on site represents the largest potentials for cost and time reductions as well as potentials for new technologies in the area of automation.

Irregular demand, great variety and high capital costs in construction require similar strategies as already 
applied in the manufacturing industry. The shorter the time span between contract signing and utilization of the building the cheaper the financing of the project. Therefore robot oriented manufacturing requires standardized planning, production and assembly systems [2].

Systems for these applications have been developed for several years, but they have not yet become generally accepted on the market. The fact that these robots frequently suffer from technical or systematic shortcomings is no secret: They are often too heavy, too ponderous and can hardly be transported within the construction site. The navigation of these systems in the chaos called construction site is still full of problems and the adherence to relevant safety standards is not yet ensured to its full extent. Nevertheless these problems do not represent insurmountable obstacles. The far larger and still hardly investigated obstacles for a considerable onsite automation are the planning issues, the subcontracting structures and the site organization.

However the need for more efficiency in the construction sector is not the only reason for considerable automation: There is still a multitude of uncomfortable, hard, partial unreasonable and dangerous jobs on the construction site. The statistics of construction associations and social security institutions regarding accidents at work, occupational illness and long-term disability of building workers clearly characterise the situation. Here automation can make a substantial contribution to humanization and ergonomic improvement of working processes, if this aspect is considered in the design of the machines and devices. Not least the need for quality improvement in the building industry is to be mentioned, where the application of robots and the associated propagation of efficient procedures will contribute to a higher quality of end products.

\section{DESIGN OF A ROBOT FOR FIXING ATTACHMENTS TO CEILING SLABS}

The motivation for the following considerations was the task to develop optimal basic conditions for the efficient application of a robot for the fixing of attachments to concrete ceiling slabs. Structure and mode of operation of the system are described in detail in [3], therefore only the substantial characteristics are mentioned here:

The basis is a modular concept: Alternative process units for different assembly operations can be mounted on a flexible transportation unit. The components transportation unit and process unit for ceiling attachment were selected for further development and production of a prototype.
Because of the multitude of obstacles on the floor, it was decided to use a track vehicle as transportation module. Navigation is realized by an image processing system mounted on the transportation module detecting the chalk line which had been applied manually on the floor. So the machine is able to follow the line and to detect the marked points of operation.

The travel on site and the change from one chalk line to the other are controlled by the user with a joystick. At the point of operation the process module drills the borehole into the concrete ceiling, fixes subsequently a pin or a dowel, and assembles the suspension rod for a suspended ceiling system.

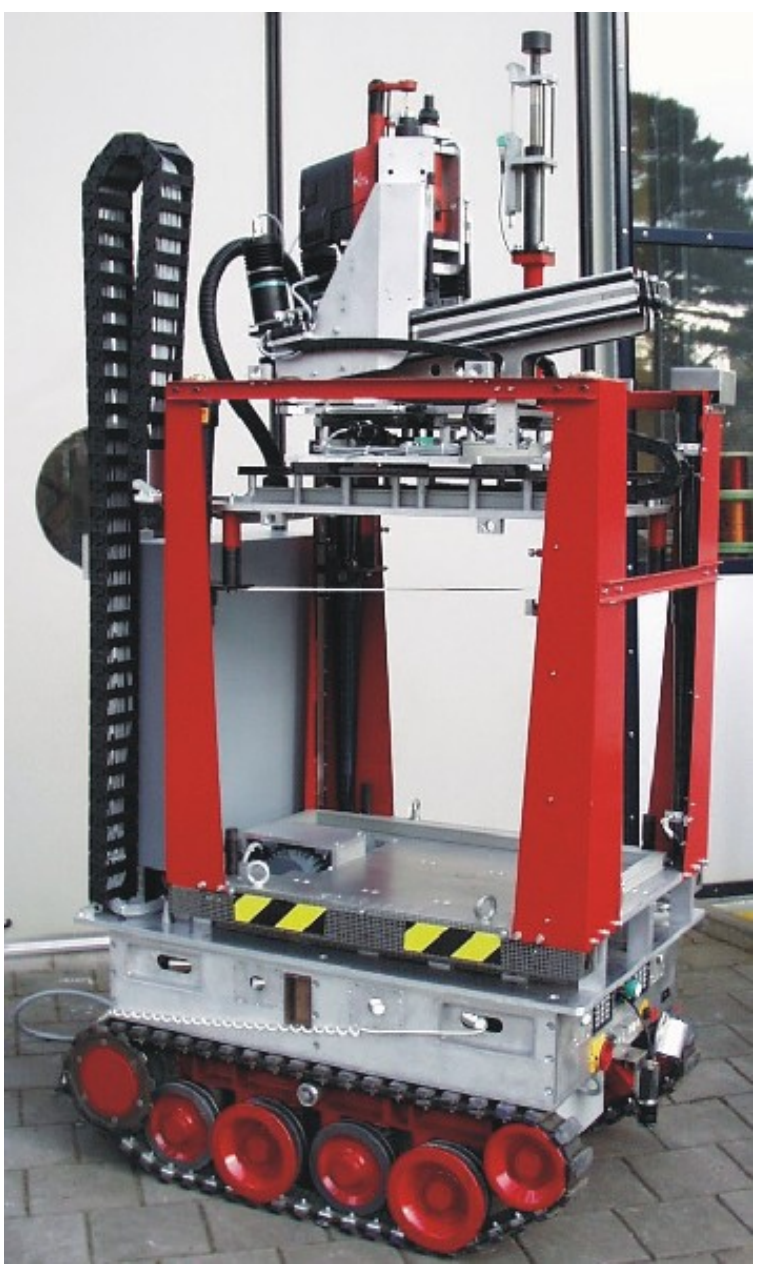

Figure 1. Prototype of a modular robot system

In order to perform these tasks the prototype comprises several lifting mechanisms, a conventional hammer drill, and a conventional device for fixing bolts. Sensor technology and computer control ensure the fine positioning and the perpendicular transfer of the point of operation from the soil to the ceiling. 
This device was developed as a prototype in the context of a research project. While testing it on several building sites it was recognized that many prerequisites in the aspects of planning, subcontracting structure and site organisation are opposed to an economic application of the new technology. A further development and optimization of techniques is not sufficient: new planning methods and adapted methods of site organisation are to be found in order to enable automation on the building site at all! Additionally it was realized that the application of the new machinery will be impossible without special knowledge of planners and contractors.

Therefore tools and aids have to be created, which enable all involved parties to apply such new construction techniques.

\section{OBSTACLES FOR AN AUTOMATION OF THE BUILDING SITE}

\subsection{Awareness of the Robots' Requirements}

The planners are not aware of the requirements of robots and machines. The application of a robot on the building site makes accurate demands on planning and execution of the project: For example the dimensions of the device (width, length, height and weight) are to be considered, the availability of a freight elevator has to be taken into consideration etc. The knowledge of these prerequisites in the planning stages of the project, however, cannot be taken for granted, rather a system of information and training has to be developed and offered.

\subsection{Obstacles at the Location of Robotic Assembly}

The highly mobile and flexible human worker can get along with installations on the floor, huddles of building material and stored tools without significant problems. Such obstacles in large quantities are common practice on today's building site. For a robot however they represent an enormous handicap, if not even a prevention from its operational performance.

\subsection{Too Small Working Sections for the Robot}

Used at a late point of time in building process, no larger and connected working sections remain for the robots. For example when using the maschine only for the assembly of the attachment of suspended ceilings, the robot has to deal with many light construction walls, wich are rigged up before. Taking the common case of an office building including many single offices on both sides of a long corridor, the robot will find working areas not larger than approx. 10-15 square meters. Here an effective application of the unit is completely impossible.

\subsection{Planless Allocation of the Assembly Places.}

Today the flow of the assembly processes in a space with different assembly troops is being planned only in small measure. There are only few processes, which require an exclusive allocation. The machine in contrast is able to operate within a certain area only alone and requires therefore a higher degree of organization in building site planning.

\subsection{The Conventional Component-Oriented Trade Structure Handicaps the Extent of Automation.}

The implemented prototype would be able to complete all attachments, which can be brought in the concrete ceiling, in a single processing step. In reality the device was used only by a company for interior fittings, all other possible work, such as adjustment of domestic engineering was done by manual work.

\section{AUTOMATION-ORIENTED PROJECT PLANNING}

Thus an efficient use of robots on-site can be only guaranteed, if its rules and requirements are considered already in planning. In the following chapters planning principles and requirements for automated construction will be shown:

\subsection{Creation of New Planner- and Trade Structures}

The conventional component- and product-oriented separation of planners (architect, engineer for building services, electrical engineer, etc.) and trades (sanitary, heating, electrical installation, interior works for suspended ceilings and walls, etc.) suffices no longer. The process orientation of the robots requires a process orientated organization of planning and realization!

4.1.1. Regarding the planning as a new engineering profession (like an engineer for physics in construction or other special engineers) could care for the automation know-how and the needed coordination between the other planners in the project team.

Automation engineers would perform the following tasks:

\footnotetext{
Specification of task criteria for the planners

Expert advice during the design process

Examination of all plannings concerning its special criteria

Generating specific data such as project specifications of pure machine trades.
} 
These partial tasks are taken away from the classical task profiles of different other engineers. Here the problem has to be solved how to organize fees.

Naturally this task also could be taken over by the coordinating architect or another planning engineer, both educated and qualified in the field of automation. In this case they do a "special service", which requires supplemental fees.

4.1.2. Concerning the executing companies, like the planners, a rearrangement of tasks from several existing trades to new trades has to take place. Here a company for interior fittings also could overtake the tasks of roboting as well.

This is described by the example of the tested assemly robot:

The machine is able to do drillings in the concrete ceiling automatically, to set dowels or pins for the attachment of components and finally to attach different subsystems e.g. suspension rods of suspended ceilings. In the optimal case it should be allowed and able to do the tasks of all involved trades, among which are counted the attachments for electrical lines as well as the clips for water and heater pipes or the sub-construction for suspended ceilings and many other items from various internal trades.

This optimum could be gained only by the creation of a new trade "attachment technique", which takes over the partial task "attachment of sub-constructions to concrete ceilings" from many other trades. Of course many problems have to be considered: Guarantee questions, concrete definition of the task, quality standards needed by the subsequent works, standardization of all suspension components, tolerances, etc.

For first implementations of such a scenario the assignment of a general contractor seems to be useful, primarily a larger company, which can apply the initial investment for the robot and execute the operations itself.

\subsection{All Planners Compile a Common Building Model on CAD Systems}

For the robot trade the planning specification of different engineers has to be unified. This determines the creation of a common digital building model. Apart from the fact that this should be required for each planning by the reason of increasing effectiveness, in automation arise additional rationalization potentials as a result of this measure: The use of computer controlled assembly devices offers for the first time the possibility of a constant data flow from planning to the execution on construction sites!

\subsection{Use of Building Elements in Computer Aided Planning}

In order to ensure a strict data flow from planning to realization, technical draughtsmen could use the CAD-element method.

This method applies pre-defined building elements, which have to be used by all programs and have to be to all planners' disposal. The building elements can be offered by individual producers of CAD-system according to general standards. It is also imaginable that component producers or realizing companies offer CAD-building elements in form of product catalogues. In both cases these elements make it possible to create defined interfaces with regard to data transfer into other planning areas (e.g. mass determination, room equipment catalogue, submission, calculation, calculations of building physics, etc..). In this case a defined interface to the realizing company is of special relevance: the data model of the planning enables the contractor of the robot craft now, to attach his data for preparatory work (materials allocation, personnel planning, logistics, etc..) and even working data for the robots (drilling positions, driving data determination and optimization, material supply, collision calculations, etc.). Just as in manufacturing, robots and automated plant only become advantageous when properly integrated into an appropriate IT infrastructure which links design to manufacture [4].

The rationalization and optimization potential within this peripheral area can surely be estimated just as largely as the saving possibilities by the robot work itself!

\subsection{Completed Realization Planning and Assignment Before Building.}

In other industries this request is considered as a matter of course, whereas in building industry it is stringent by no means. Due to time reasons one frequently operates on a parallel, timely deferred planning and realization, which turns out on closer inspection and in most cases as a false methodology. In any case the disadvantages of this method within the scope of a conventional project should not be mentioned more detailed here. This request is indispensable for the realization of an automated building site, because pre-fabrication of components, which are installed at the end of realisation, have to be done at a very early point in time. In the case of robots for ceiling fixations borings for the adjustment of the sanitary pipes for example have to be brought in combined with the pins for suspended ceilings. Here pre-working of the sanitary installation, proceeding very early in building flow, and the dry construction assembly taking place substantially later, are realized at the same time. The planning of the interior fitting has to be finished immediately after the completion of the shell, i.e. by the time of the robot assembly! 


\subsection{Building Process Planning with Consideration of Robot-Specific Requests}

Each automated assembly sequence contains special demands to the building site flow and the building site organization and requires an individually adapted methodology of the management in each case. The ceiling-doweler for example has to be used directly after the completion of the shell. It has to perform necessary work very early and at this time it meets only a minimum of driving and assembly obstacles. Additionally its possible working sections are substantially larger by the absence of light partitions than at a later point in time. As a result of time studies during assembling, this factor has an enormous impact on the cycle time of the device. The increase of preparation and changing times on surfaces getting smaller can lead up to the inefficiency of the entire work. Due to the high capital investments, caused by a robot, attention has to be paid to a preferable non-stop utilization of the device. With regard to the organization of the building progress in components or in levels relevance has to be ascribed to this fact.

\subsection{Central Measurement of the Shell and Nominal/Actual Alignment}

The demand for a measurement of the shell on the part of the principal to a correct quality control as well as to a status statement of all subsequent work seems to be a matter of course - however it is not always applied in the building industry. This method is essential to the efficient use of robots:

The adjustment of the theoretical building model of planning to the built reality is necessary for the generation of the correct driving and working data. Additionally thereby an early and coordinated reaction on realisation errors is possible for all subsequent systems.

\section{RESULTS}

The results obtained in the investigation show that extensive research work has to be done in the field of planning and building management to introduce robots on the building site successfully. This can give the impression substantial interventions in proven procedures and operational sequences have to be proposed at the expense of all project participants only to make possible a technological break-through. But first of all the virulent requirements of more efficient and more ergonomic methods in the building industry, mentioned in the introduction, are one reason against. Secondly an exact consideration of the demands of a robot-based project structure illustrates this concerns generally improvements of planning, which can also lead to a substantial quality increase even without the use of machines. Thus automation connected with information technology assists in a significantly improving existing work processes by redesigning them [5].

Altogether more economical building, more ergonomic conditions for the workers, a qualitatively high-valued result and a substantially more structured process of project can be expected facilitating the often conflict-loaded building everyday life for all participants.

\section{REFERENCES}

[1] M. Dalacker, "Entwurf und Erprobung eines mobilen Roboters zur automatisierten Erstellung von Mauerwerk auf der Baustelle", Schriftenreihe Planung, Technologie, Management und Automatisierung im Bauwesen, Band 1, Fraunhofer IRB Verlag, Stuttgart, 1997.

[2] T. Bock, Robot Oriented Design, Shokokusha, Tokio, May 1988.

[3] K. Feldmann, M. Koch, "Development of an open and modular control system for autonomous mobile building robots with flexible manipulators", to be published at the 17 th International Symposium on Automation and Robotics in Construction, September 2000.

[4] D. Seward, S. Quayle, "Global integration of construction automation and robotics", Proceedings of the $16^{\text {th }}$ International Symposium on Automation and Robotics in Construction, Madrid, 1999.

[5] R.E. Johnson, M.J. Clayton, "The impact of information technology in design and construction: the owner's perspective", Automation in Construction, Vol.8, Nr. 1, Elsevier, 1998. 